\title{
Inhibition of Hepatic Triglyceride Formation by Clofibrate
}

\author{
Larry L. Adams, William W. Webb, and Harold J. Fallon \\ From the Departments of Medicine and Pharmacology, University of Norlh \\ Carolina School of Medicine, Chapel Hill, North Carolina 27514
}

\begin{abstract}
A в S T R A C T The effect of clofibrate (CPIB) on hepatic glycerolipid formation has been studied in vivo and in vitro in the rat. Feeding $0.25 \%$ CPIB in laboratory chow significantly reduced serum triglyceride levels by $6 \mathrm{hr}$ and concomitantly decreased the rate of glycerol${ }^{14} \mathrm{C}$ incorporation into hepatic and serum glycerides, in vivo. These changes persisted for at least 14 days. A similar decrease in serum triglyceride and glycerol incorporation into hepatic glycerides was observed in rats fed high glucose diets containing $0.25 \%$ CPIB. Serum glycerol was reduced by feeding CPIB for 14 days. The formation of diglyceride and triglyceride from ${ }^{14} \mathrm{C}$-snglycerol-3-P by rat liver homogenates was inhibited by addition of 1-40 mM CPIB to the reaction mixture. These results suggest that CPIB reduces hepatic glycerolipid synthesis, possibly by inhibition of one or more reactions in the esterification of sn-glycerol-3-P. This change may account for the early fall in serum triglyceride. At later time periods, serum glycerol levels fall and in some experiments, hepatic triglyceride content increases. Therefore, it is likely that additional metabolic alterations may contribute to the sustained hypotriglyceridemic effects of CPIB.
\end{abstract}

\section{INTRODUCTION}

Ethyl chlorophenoxyisobutyrate (clofibrate or CPIB) ${ }^{1}$ reduces the serum level of triglyceride and, less fre-

This work appeared in abstract form at the Annual Meeting of the American Federation for Clinical Research, Atlantic City, N. J., May 1970 (1).

Mr. Adams was supported by a Fellowship from the Pharmaceutical Manufacturers' Association.

Dr. Fallon received an award from the Burroughs-Wellcome Foundation.

Received for publication 26 October 1970 and in revised form 10 May 1971.

${ }^{1}$ Abbreviations used in this paper: CDP, cytidine diphosphate; CPIB, ethyl chlorophenoxyisobutyrate (clofibrate); TLC, thin-layer chromatography. quently, cholesterol in humans and animals $(2,3)$. It is reported that CPIB inhibits hepatic cholesterol synthesis in treated animals $(4,5)$. However, the mechanism by which the drug reduces serum triglyceride is uncertain. Multiple potential modes of action have been suggested and include; an increased uptake of serum triglyceride by adipose tissue (6); a decrease in fatty acid release from adipose tissue (7) manifested by reduced serum free fatty acid levels (8); a reduction in the rate of hepatic triglyceride release (9-12); and inhibition of hepatic fatty acid synthesis (13). Changes in the distribution of thyroid hormone also have been postulated as a mode of action for CPIB (14). However, other possible mechanisms for the reduction in serum triglyceride by CPIB have not been excluded.

The liver is the primary source of serum triglyceride in the postabsorptive state. Therefore, suppression of hepatic triglyceride synthesis should result in reduction of serum triglyceride levels. Previous investigators did not observe inhibition of triglyceride formation in the liver of rats fed CPIB (10). However, the present studies demonstrate a significant reduction in hepatic diglyceride, triglyceride, and lecithin formation from glycerol, measured in vivo, in rats given CPIB. Furthermore, CPIB inhibited diglyceride and triglyceride synthesis from sn-glycerol-3-P by liver homogenates. The inhibition in triglyceride formation correlates temporally with the fall in serum triglyceride and precedes changes in serum glycerol levels. These results suggest that inhibition of hepatic glycerolipid synthesis contributes to the lowering of serum triglyceride observed in rats given CPIB.

\section{METHODS}

Male adult Sprague-Dawley rats weighing 200-250 g were used in all studies. The rats were individually caged and killed by exsanguination without fasting. The CPIB $(0.25$ $\mathrm{g} / 100 \mathrm{~g}$ chow) was dissolved in diethyl ether and mixed in ground Purina Rat Chow as described previously (5). 
In one experiment, CPIB $(0.25 \mathrm{~g} / 100 \mathrm{~g}$ diet $)$ was mixed with a diet containing $64 \%$ glucose (15). Experimental rats were fed ad lib. for $6 \mathrm{hr}$ to 14 days and control animals were pair fed the same diets without CPIB.

After 14 days, both control and experimental animals were injected either intraperitoneally or intravenously with $0.5 \mathrm{ml}$ isotonic saline containing $5 \mu \mathrm{Ci}$ of $1-3$, glycerol $-{ }^{14} \mathrm{C}(6.5 \mu \mathrm{Ci}$ ) $\mu$ mole) obtained from New England Nuclear Corp, Boston, Mass. 17 min later, the animals were anesthetized with ether, the abdomen opened, and $6-12 \mathrm{ml}$ of blood withdrawn from the dorsal aorta and placed in ice. The livers were removed quickly, frozen in liquid nitrogen, and stored at $-40^{\circ} \mathrm{C}$. The hepatic lipids were extracted, separated by thin-layer chromatography, and radioactivity determined as reported earlier (6). Hepatic and serum triglyceride and diglyceride content was determined by dichromate reduction (17) after separation by thin-layer chromatography (TLC) or by an automated modification of the method of van Handel and Zilversmit (18). An estimation of the rate of glycerol incorporation into glycerides was derived from the following equation;

glyceride formed $/ 17 \mathrm{~min}=$

\section{$\mathrm{dpm}$ in hepatic glyceride/g liver specific activity serum glycerol $(\mathrm{dpm} / \mu$ mole $)$}

Serum glycerol concentration was determined as described by Laurell and Tibbling (19) except the samples were deproteinized by dilution with an equal volume of water and boiling in water for $5 \mathrm{~min}$.

Serum glycerol radioactivity was determined after separation from glucose by thin-layer chromatography on microcrystalline cellulose plates (Brinkmann Instruments, Inc., Westbury, N. Y.). The solvent system was water, butyl alcohol, and acetic acid $(5: 4: 1)$. Glycerol was separated from glucose and sn-glycerol-3-P. The glycerol was eluted from the cellulose with methyl alcohol, the solvent removed by evaporation under $\mathrm{N}_{2}$ and the remaining glycerol dissolved in scintillation counting fluid (Liquifluor and toluene $1: 24)$.

The incorporation of ${ }^{14} \mathrm{C}$-sn-glycerol-3-P into lipids by preparations of rat liver was measured by a modification of earlier techniques (15). The liver homogenates were prepared in 4 vol of $0.25 \mathrm{M}$ sucrose containing $0.01 \mathrm{M}$ Tris$\mathrm{HCl}$ buffer, $\mathrm{pH}$ 7.5. After centrifugcation at $4^{\circ} \mathrm{C}$ for 10 $\mathrm{min}, 0.2 \mathrm{ml}$ of the supernatant was incubated for $15 \mathrm{~min}$ at $37^{\circ} \mathrm{C}$ with $50 \mathrm{~mm} \mathrm{KCl}, 20 \mathrm{~mm}$ Tris- $\mathrm{HCl} \mathrm{pH} 7.5,3.6$ $\mathrm{mM} \mathrm{MgCl}_{2}, 3.6 \mathrm{~mm}$ ATP, $0.7 \mathrm{~mm}$ dithiothreitol, $40 \mu \mathrm{M}$ CoA, $2.5 \mathrm{mg}$ of albumin, $1.42 \mathrm{~mm} \mathrm{Na}$ palmitate, and 0.12 $\mathrm{mm}{ }^{14} \mathrm{C}$-sn-glycerol-3-P $(0.1 \mu \mathrm{Ci})$ in a total volume of $0.7 \mathrm{ml}$. CPIB was added as the $\mathrm{Na}$ salt dissolved in $0.01 \mathrm{M}$ Tris- $\mathrm{HCl} \mathrm{pH}$ 7.5. The reaction was stopped by adding 10 $\mathrm{ml}$ of chloroform-methanol $(2: 1, \mathrm{v} / \mathrm{v})$. Lipids were extracted and separated by TLC as described previously (15, 16). Radioactivity was determined by liquid scintillation spectroscopy. The incorporation of palmitate ${ }^{14} \mathrm{C}(0.2 \mu \mathrm{Ci})$ into hepatic lipids was measured under identical assay conditions except that the concentration of sn-glycerol-3-P was $5 \mathrm{~mm}$.

The location of the radioactive label in the triglyceride formed in vivo and in vitro was determined. Triglyceride was separated by TLC, scraped and eluted from the silica gel with chloroform: methanol $(2: 1)$ and subjected to methanolysis (20). Radioactivity in the glycerol and fatty acid products was determined after appropriate TLC separation.
Glycerokinase determination was based on the methods of Robinson and Newsholme (21) and Newsholme, Robinson, and Taylor (22). The homogenate was incubated for $5 \mathrm{~min}$ with $85 \mathrm{~mm}$ Tris- $\mathrm{HCl}, 1.25 \mathrm{~mm}$ EDTA, $21 \mathrm{~mm} \mathrm{NaF}, 17$ $\mathrm{mm}$ dithiothreitol, $3.6 \mathrm{~mm}$ ATP, $3.4 \mathrm{~mm} \mathrm{MgSO}_{4}$, and 0.3 $\mu \mathrm{Ci}$ glycerol $-{ }^{14} \mathrm{C}$ in a total volume of $0.28 \mathrm{ml}$. The product, sn- ${ }^{14} \mathrm{C}$-glycerol-3-P was recovered on a DEAE-cellulose paper disc $(21,22)$. Activity of the enzyme was proportional to time of incubation and enzyme concentration under these conditions.

Long-chain acyl CoA synthetase activity was measured in liver homogenates as described by Wittels and Bressler (23), and diglyceride acyltransferase by the method of Young and Lynen (24). Serum CPIB levels were determined in one experiment (25). Protein was estimated by the method of Lowry, Rosebrough, Farr, and Randall (26). All data were analyzed by the standard $t$ test with variance estimated by standard error mean (SEM).

$1-3$, glycerol $-{ }^{14} \mathrm{C}$ was purchased from New England $\mathrm{Nu}-$ clear Corp. and over $98 \%$ of the radioactivity in this product was chromatographically identical to glycerol. Lipid standards were purchased from Applied Science Labs, Inc, State College, $\mathrm{Pa}$. All other reagents were obtained from regular commercial sources. CPIB ethyl ester and $\mathrm{Na}$ salt was kindly provided by Dr. J. Noble of Ayerst Laboratories, New York.

\section{RESULTS}

The administration of CPIB for 2 wk resulted in a decrease of $38 \%$ in mean serum triglyceride levels as shown in Table I. Hepatic triglyceride content was increased in rats given CPIB for 14 days in these two experiments. However, the level of hepatic triglyceride was variable and ranged from a decrease of $30 \%$ to an increase of $40 \%$ in multiple experiments. Similar variable changes in liver triglycerides have been reported in rats fed chow diets plus CPIB $(5,10,27-30)$.

There was no significant variation in total body weight or rate of weight gain between the controls and experimental animals. An increase of $22 \%$ in mean liver weight occurred in rats fed CPIB, which is in good agreement with earlier studies $(4,10)$. The serum concentration of CPIB varied from 0.5 to $1.7 \mathrm{~mm}$ after 14 days of treatment with CPIB.

The concentration of serum glycerol in the control and treated animals at the end of $2 \mathrm{wk}$ is shown in Table I. The level of serum glycerol was regularly lower in the rats given CPIB.

Triglyceride synthesis in vivo. The incorporation of glycerol- ${ }^{14} \mathrm{C}$ into hepatic and serum triglyceride was measured in control rats and rats fed CPIB. To determine the optimum time intervals for estimation of glyceride synthetic rate, the incorporation of glycerol- ${ }^{14} \mathrm{C}$ into hepatic triglyceride was measured at various times up to $1 \mathrm{hr}$ in control rats and rats fed CPIB. Maximum radioactivity was found in hepatic triglyceride $15-30 \mathrm{~min}$ after intraperitoneal or intravenous administration of glycerol- ${ }^{14} \mathrm{C}$ in both groups (Fig. 1). Therefore, a time period of $17 \mathrm{~min}$ was chosen for these calculations. 
TABLE I

Effects of CPIB on Hepatic and Serum Triglycerides, Serum Glycerol, and Liver Weight

\begin{tabular}{|c|c|c|c|c|c|c|c|c|}
\hline Experiment & $\begin{array}{c}\text { Serum } \\
\text { triglyceride }\end{array}$ & & $\begin{array}{c}\text { Liver } \\
\text { triglyceride }\end{array}$ & & Liver weight & & Serum glycerol & \\
\hline$\stackrel{n}{\text { Control (10) }}$ & $\begin{array}{c}m g / 100 m l \pm \text { SEM } \\
100.5 \pm 8.6\end{array}$ & $P$ & $\begin{array}{c}m g / g \pm \mathrm{SEM} \\
4.07 \pm 0.34\end{array}$ & $P$ & $\begin{array}{c}g \pm \text { SEM } \\
13.1 \pm 0.62\end{array}$ & $P$ & $\begin{array}{c}n \text { moles } / m l \pm \text { SEM } \\
137.7 \pm 8.0\end{array}$ & $P$ \\
\hline CPIB (15) & $61.6 \pm 5.9$ & $<0.001$ & $5.89 \pm 0.35$ & $<0.005$ & $16.9 \pm 0.58$ & $<0.005$ & $96.5 \pm 3.1$ & $<0.025$ \\
\hline Control (12) & $84.7 \pm 9.3$ & & $3.86 \pm 0.27$ & & $10.0 \pm 0.57$ & & $136.6 \pm 3.5$ & \\
\hline CPIB (13) & $53.0 \pm 3.8$ & $<0.01$ & $6.30 \pm 0.58$ & $<0.005$ & $12.8 \pm 0.61$ & $<0.001$ & $104.2 \pm 3.5$ & $<0.005$ \\
\hline
\end{tabular}

Serum triglyceride concentration is expressed as $\mathrm{mg}$ triglyceride $/ 100 \mathrm{ml}$ serum $\pm \mathrm{SEM}$; liver triglyceride content as milligrams triglyceride/gram wet weight of liver $\pm \mathrm{SEM}$; and liver weight as grams $\pm \mathrm{SEM}$. Rats given CPIB for 14 days showed a mean decrease of 39 and $37 \%$ in serum triglyceride levels in two separate experiments. The CPIB groups showed mean increases of 31 and $39 \%$ in liver triglyceride content and a $22 \%$ increase in liver weight. Glycerol concentration is expressed in nanomoles/ milliliter serum \pm SEM. $P$ values are given for differences between control and CPIB groups.

Determinations of the specific activity of serum glycerol was necessary for calculation of the rate of glycerol incorporation into hepatic triglyceride. After the first $2 \mathrm{~min}$, the radioactivity present in glycerol was stable throughout the $17 \mathrm{~min}$ interval. Therefore, calculations were based on the serum glycerol specific activity at $17 \mathrm{~min}$. The rate of glycerol incorporation into hepatic triglyceride was estimated from the specific activity of serum glycerol and the total radioactivity of the hepatic glyceride fractions in $1 \mathrm{~g}$ of liver $17 \mathrm{~min}$ after administration of glycerol- $-{ }^{14} \mathrm{C}$. The results are shown in Table II.

The formation of triglyceride and diglyceride from glycerol was decreased approximately $50 \%$ in rats given CPIB. Since CPIB increased liver weight, glycerol incorporation rates were calculated in terms of total liver weight. The differences between control rats and rats given CPIB were less marked when calculated in this manner but were still significant. Lecithin forma-

TABLE II

Effect of CPIB on Hepatic Glycerolipid Synthesis In Vivo from Glycerol-14 $\mathrm{C}$

\begin{tabular}{lcccc}
\hline Experiment & $\begin{array}{c}\text { Triglyceride } \\
\text { per } \mathrm{g} \\
\text { liver }\end{array}$ & $\begin{array}{c}\text { Triglyceride } \\
\text { per total } \\
\text { liver }\end{array}$ & $\begin{array}{c}\text { Diglyceride } \\
\text { per } \mathrm{g} \\
\text { liver }\end{array}$ & $\begin{array}{c}\text { Lecithin } \\
\text { per } \mathrm{g} \\
\text { liver }\end{array}$ \\
\hline \multicolumn{1}{c}{$n$} & nmoles $/ 17$ & mmoles $/ 17$ & nmoles $/ 17$ & nmoies $/ 17$ \\
min \pm SEM & min \pm SEM & min \pm SEM & min \pm SEM \\
Control (10) & $114.8 \pm 14.8$ & $1.15 \pm 0.17$ & $23.4 \pm 4.8$ & $77.4 \pm 11.4$ \\
CPIB (15) & $55.6 \pm 8.0$ & $0.73 \pm 0.12$ & $12.2 \pm 1.6$ & $50.8 \pm 4.8$ \\
$\%$ Decrease & $52 \%$ & $36 \%$ & $48 \%$ & $34 \%$ \\
$P$ & $P<0.001$ & $P<0.05$ & $P<0.025$ & $P<0.025$
\end{tabular}

The estimated pipid synthetic rate is expressed as nmoles of glycerolipid/g of wet weight of liver per $17 \mathrm{~min}$ 土SEM after intraperitoneal injection of glycerol-14C. In column two, the estimated triglyceride synthetic rate is multiplied by the liver weight in grams. The estimated synthetic rate was calculated as described in methods. Rats were fed CPIB for 14 days. tion from glycerol was also determined by this technique and was depressed $34 \%$ in rats given CPIB. The reduction of diglyceride and lecithin formation was quantitatively similar to the decrease in triglyceride formed, suggesting that CPIB may inhibit a reaction common to the formation of these glycerolipids.

A decreased rate of glycerol uptake by the liver might contribute to these findings, and therefore, the effect of CPIB administration on hepatic glycerokinase activity and the rate of glycerol- ${ }^{14} \mathrm{C}$ disappearance from plasma was measured. The mean value for glycerokinase activity in rats fed CPIB for 14 days was 8.8 nmoles sn-glycerol-3-P formed $/ \mathrm{mg}$ protein per $\min \pm 1.0 \mathrm{SEM}$ and $8.6 \mathrm{nmoles} / \mathrm{mg}$ protein per $\min \pm 0.5 \mathrm{sEM}$ for the control group. This difference was not significant. Addition of $20 \mathrm{~mm}$ CPIB to the incubation mixture did not

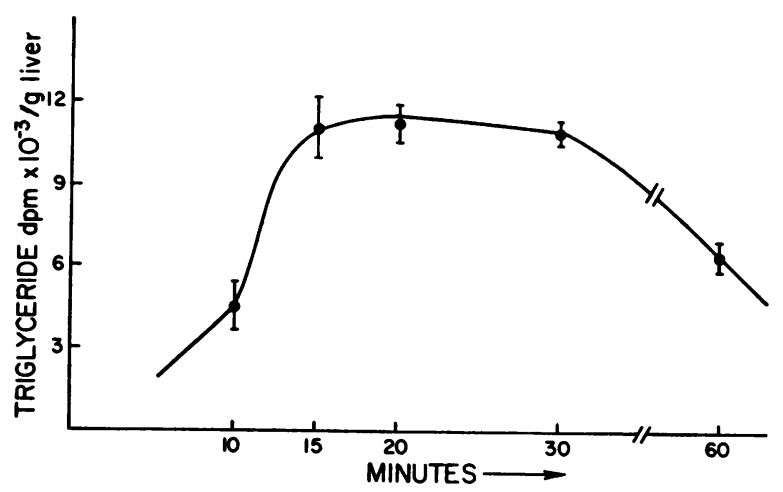

Figure 1 The time course of glycerol ${ }^{14} \mathrm{C}$ incorporation into hepatic triglyceride. Four rats were injected intraperitoneally with glycerol $-{ }^{14} \mathrm{C}$ at each of the above time intervals. Radioactivity in triglyceride reached a maximum between 15 and $30 \mathrm{~min}$ with a gradual decline occurring thereafter. Similar results were obtained when the glycerol${ }^{14} \mathrm{C}$ was given intravenously to normal rats or rats fed CPIB. 


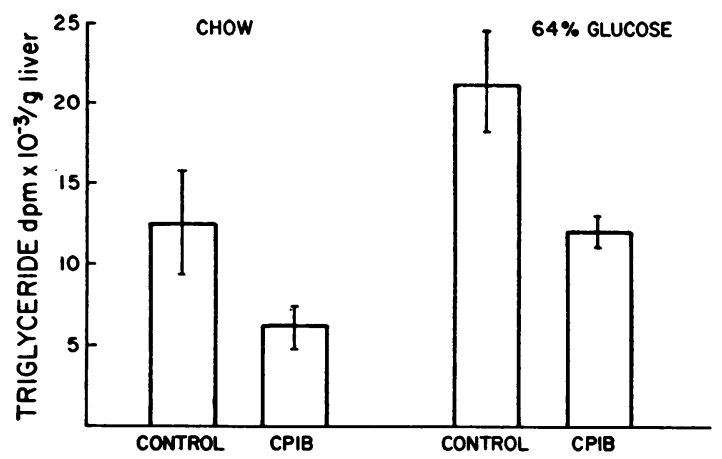

FIGURE 2 Triglyceride synthesis in animals given CPIB. Eight animals in each of the four groups were fed the appropriate diet for $2 \mathrm{wk}$. Glycerol- ${ }^{14} \mathrm{C}$ incorporation into hepatic triglyceride in the CPIB treated rats was significantly less than the corresponding control in both diet groups $(P<0.025)$. Incorporation into triglyceride was significantly increased in animals fed $64 \%$ glucose compared with those fed laboratory chow with or without addition of CPIB $(P<0.05)$. The hepatic triglyceride concentration was $10.3 \pm 1.1 \mathrm{mg} / \mathrm{g}$ in rats fed $64 \%$ glucose and this increased to $14.9 \pm 2.1 \mathrm{mg} / \mathrm{g}$ in those fed the same diet plus CPIB for 14 days.

inhibit glycerokinase activity. The specific activity of serum glycerol remained constant from 2 to $17 \mathrm{~min}$ in both control and CPIB animals. The rate of glycerol $-{ }^{14} \mathrm{C}$ disappearance from plasma from 20 to $60 \mathrm{~min}$ was also similar in the two groups.

The effect of CPIB on glycerol incorporation into hepatic triglyceride as measured, in vivo, was compared in rats fed diets containing $64 \%$ glucose or an isocaloric amount of laboratory chow. Previous studies have shown that this diet increases the capacity for hepatic trigylceride synthesis measured in vitro (15). Fig. 2 demonstrates that the $64 \%$ glucose diet increased the calculated rate of triglyceride formation from glycerol

TABLE III

Intravenous Glycerol-14C Incorporation into Hepatic and Serum Glyceride

\begin{tabular}{|c|c|c|c|c|}
\hline \multirow[b]{2}{*}{ Experiment } & \multicolumn{2}{|c|}{ Serum } & \multicolumn{2}{|c|}{ Liver } \\
\hline & $\begin{array}{l}\text { Triglyceride } \\
\text { per } \mathrm{ml}\end{array}$ & $\begin{array}{l}\text { Diglyceride } \\
\text { per ml }\end{array}$ & $\begin{array}{c}\text { Triglyceride } \\
\text { per } \mathbf{g}\end{array}$ & $\begin{array}{l}\text { Triglyceride } \\
\text { per total } \\
\text { liver wt }\end{array}$ \\
\hline$n$ & $\begin{array}{l}\text { nmoles } / 17 \\
\min \pm \mathrm{SEM}\end{array}$ & $\begin{array}{l}\text { nmoles } / 17 \\
\min \pm \text { SEM }\end{array}$ & $\begin{array}{l}\text { nmoles/17 } \\
\min \pm \mathrm{SEM}\end{array}$ & $\begin{array}{c}n m o l e s / 17 \\
\min \pm \mathrm{SEM}\end{array}$ \\
\hline $\begin{array}{l}\text { Control (12) } \\
\text { CPIB (13) } \\
\% \text { Decrease } \\
P\end{array}$ & $\begin{array}{c}20.0 \pm 3.0 \\
9.2 \pm 1.8 \\
54 \% \\
P<0.01\end{array}$ & $\begin{array}{c}1.6 \pm 0.16 \\
0.8 \pm 0.14 \\
50 \% \\
P<0.005\end{array}$ & $\begin{array}{c}39.6 \pm 5.2 \\
19.0 \pm 3.2 \\
52 \% \\
P<0.001\end{array}$ & $\begin{array}{c}523.4 \pm 78.4 \\
318.2 \pm 53.4 \\
39 \% \\
P<0.025\end{array}$ \\
\hline
\end{tabular}

The rate of serum glyceride formation is expressed as nmoles of glyceride $/ \mathrm{ml}$ serum per $17 \mathrm{~min}$ 士SEM. Hepatic glyceride synthesis calculated as nmoles triglyceride/g wet weight of liver per $17 \mathrm{~min} \pm \mathrm{SEM}$. Glycerol-14C was administered intravenously. Estimated synthetic rate was calculated as described in methods. Rats were fed CPIB for 14 days. nearly twofold over control rats fed chow. CPIB administration reduced triglyceride formation $50 \%$ in rats fed the regular chow diet and $43 \%$ in those fed the high glucose diet $(P<0.025)$. Thus, CPIB did not prevent the rise in triglyceride formation produced by high glucose feeding but decreased glycerol incorporation into triglyceride proportionately in both groups of rats. In this same experiment, CPIB reduced serum triglyceride levels $21 \%$ in the rats fed chow and $37 \%$ in those fed the $64 \%$ glucose.

The decrease in hepatic triglyceride synthesis in rats given CPIB was accompanied by reduced incorporation of glycerol radioactivity into serum glycerides. The rate of incorporation of glycerol $-{ }^{14} \mathrm{C}$ into serum diglycerides was reduced by $50 \%$ and into triglycerides by $54 \%$ in rats fed CPIB as shown in Table III. This reduction in serum glyceride formation correlates well with the reduction of hepatic glyceride synthesis and serum triglyceride concentration.

The early time course for the effect of CPIB on serum triglyceride levels and the estimated rate of hepatic triglyceride synthesis is shown in Fig. 3. A decline in serum triglyceride was noted as early as 6 $\mathrm{hr}$ after starting the diet containing CPIB. This decrease was maximum at $48 \mathrm{hr}$ and was sustained for at least 14 days. At $6 \mathrm{hr}$, the rate of glycerol- ${ }^{14} \mathrm{C}$ incorporation into hepatic triglyceride was reduced to approximately $50 \%$. The decrease in triglyceride formation also was maintained for 14 days. Thus, the decline in glycerol conversion to triglyceride in liver accompanies or precedes the decline in serum triglyceride. Moreover, both of these changes occurred in the absence of a change in hepatic triglyceride content and preceded the fall in serum glycerol. The concentrations of hepatic triglyceride and phospholipid and of serum

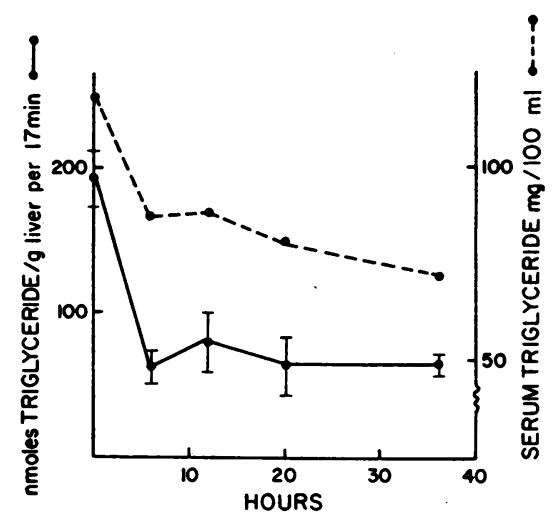

Figure 3 The effect of CPIB on glycerol- ${ }^{14} \mathrm{C}$ incorporation into hepatic triglyceride and on serum triglyceride after 6-36 hr of feeding. Values recorded are means for four rats at each time period. The $\mathrm{SE}$ is indicated for triglyceride formation. All differences from control rats are significant $(P<0.01)$. 
TABLE IV

Studies of the Early Effects of CPIB

\begin{tabular}{cccc}
\hline $\begin{array}{c}\text { Time } \\
\text { CPIB }\end{array}$ & $\begin{array}{c}\text { Liver } \\
\text { triglyceride }\end{array}$ & $\begin{array}{c}\text { Liver } \\
\text { phospholipid }\end{array}$ & $\begin{array}{c}\text { Serum } \\
\text { glycerol }\end{array}$ \\
\hline$h r$ & $m g / g$ & $\mu m o l e / g$ & $\mu m o l e / m l$ \\
0 & $6.5 \pm 1.0$ & $31.9 \pm 1.0$ & $0.19 \pm 0.02$ \\
6 & $7.1 \pm 0.5$ & $33.4 \pm 2.6$ & $0.17 \pm 0.02$ \\
12 & $5.9 \pm 0.8$ & $32.7 \pm 0.4$ & $0.20 \pm 0.01$ \\
20 & $6.6 \pm 0.4$ & $33.7 \pm 0.7$ & $0.21 \pm 0.04$ \\
36 & $6.1 \pm 0.5$ & $33.7 \pm 3.9$ & $0.20 \pm 0.03$
\end{tabular}

Levels of hepatic lipids and serum glycerol during the first 36 hr of feeding a diet containing $0.25 \%$ CPIB. Values are means \pm SEM for four rats at each time point. No differences are statistically significant. Liver triglyceride values (mg/g \pm SEM) at later time periods were as follows: day $4,7.86 \pm 0.6$; day 6 , $5.25 \pm 0.9$; day $7,6.96 \pm 0.5$; day $10,7.32 \pm 0.9$; day 12 , $7.47 \pm 2.6$; day $14,5.9 \pm 0.6$. None of these differences were statistically significant.

glycerol during the first 6-36 $\mathrm{hr}$ of feeding CPIB are shown in Table IV. There was no increase in hepatic triglyceride content measured every 2 days up to 14 days in this experiment. The specific activity of serum glycerol and hepatic sn-glycerol-3-P did not vary from controls during the initial $36 \mathrm{hr}$ of CPIB treatment.

Triglyceride synthesis in vitro. The effect of CPIB on triglyceride synthesis from ${ }^{14} \mathrm{C}$-sn-glycerol-3-P by rat liver homogenate preparations was measured at various concentrations of CPIB as illustrated in Fig. 4. Inhibition was detected at CPIB concentrations as low as $1 \mathrm{mM}$, and higher concentrations progressively decreased both diglyceride and triglyceride radioactivity. This result suggests an inhibition of in vitro glycerolipid synthesis at a step before diglyceride formation. This hypothesis was supported by the failure of added CPIB to inhibit diglyceride acyltransferase activity. The initial reaction in this assay system is the esterification of sn-glycerol-3-P by long-chain acyl CoA derivatives. The formation of the acyl CoA substrate for sn-glycerol-3-P acylation by acyl CoA synthetase also was not inhibited by CPIB in the concentration range which inhibits triglyceride formation.

The effect of varying concentrations of sn-glycerol3-P on the inhibition of glyceride synthesis by CPIB in vitro is shown in Fig. 5. Inhibition was demonstrated at substance concentrations which give maximal reaction rates in the absence of CPIB. Inhibition of lipid formation also was observed at several different concentrations of palmitate in the incubation mixture (0.5-1.4 mM). These findings suggest that CPIB may inhibit the esterification of sn-glycerol-3-P.

The capacity for triglyceride synthesis was measured in liver homogenates prepared from rats fed CPIB for 14 days. This technique estimates the over-all activity

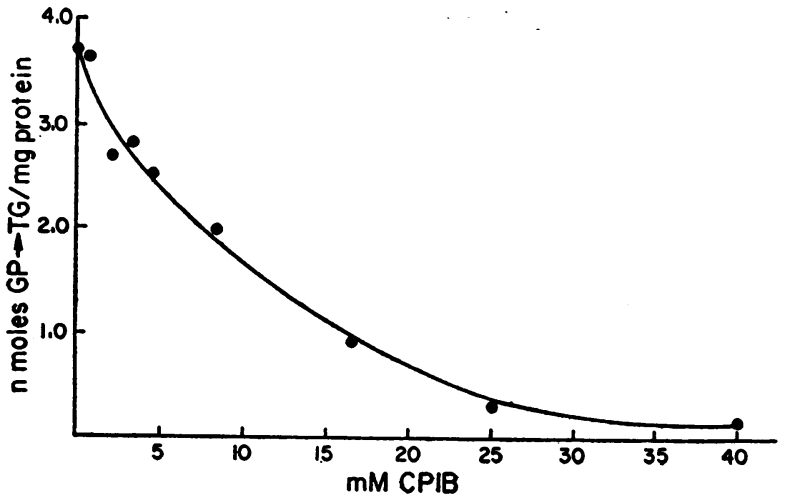

Figure 4 The formation of triglyceride from ${ }^{14} \mathrm{C}$-snglycerol-3-P by rat liver homogenates was measured as described in Methods. CPIB was added as the $\mathrm{Na}$ salt after adjustment of $\mathrm{pH}$ to 7.5. Inhibition of diglyceride formation also was observed at concentrations as low as 1-2 mм CPIB in the incubation mixture.

of the pathway under conditions of optimum substrate and cofactor concentrations in vitro. The homogenate was diluted 20 -fold before assay, reducing the content of any inhibitory compounds, such as CPIB, proportionately. To avoid variations in substrate concentration, an excess of sn-glycerol-3-P (5 mM) was added to all homogenates before assay. The incorporation of sn-glycerol-3-P into triglyceride by liver homogenates was $3.5 \mathrm{nmoles} / \mathrm{mg}$ protein per $15 \mathrm{~min}$ in

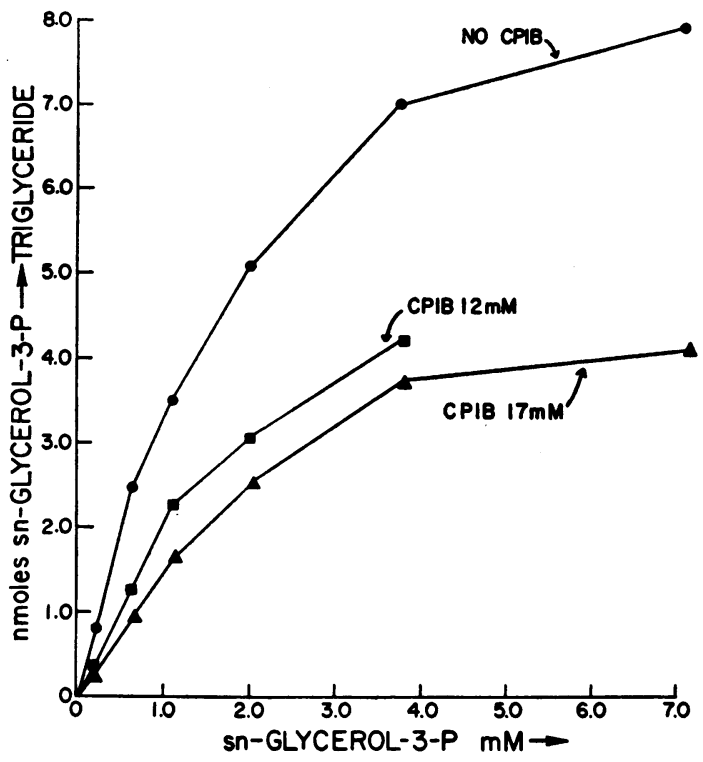

FIGURE 5 The effect of CPIB (Na salt) on the incorporation of ${ }^{14} \mathrm{C}$-sn-glycerol-3-P into triglyceride in the presence of various concentrations of sn-glycerol-3-P. This experiment was performed with a rat liver homogenate prepared from a rat fed laboratory chow. $\bullet$, no CPIB; $\Delta, 12 \mathrm{mM}$ CPIB ; $\square, 17$ mм CPIB. 


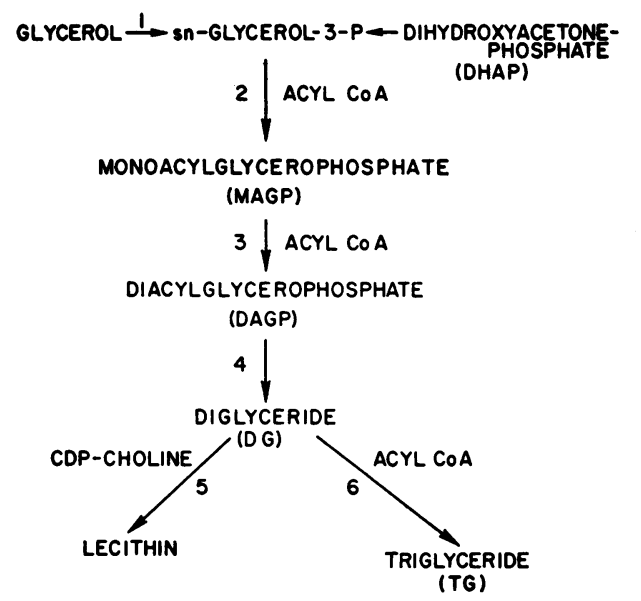

FIGURE 6 The pathway of glycerolipid formation in liver. sn-Glycerol 3-P is derived from glycerol or dihydroxyacetone phosphate. The following enzymatic reactions are shown; 1) glycerokinase, 2) sn-glycerol-3-P acyltransferase, 3) monoacylglycerol-3-P acyltransferase, 4) phosphatidate phosphohydrolase, 5) CDP choline diglyceride acyltransferase, and 6) diglyceride acyltransferase

rats fed CPIB and 3.3 nmoles/mg protein per $15 \mathrm{~min}$ for the controls. This difference was not significant.

\section{DISCUSSION}

Previous studies have suggested several possible mechanisms for the decrease in serum triglyceride levels produced by CPIB. Accelerated lipid clearance, suppression of adipose tissue lipolysis, inhibition of fatty acid synthesis, and reduced hepatic lipoprotein synthesis or release $(12,31)$ have been observed in experiments conducted in vitro or in vivo. A previous study of hepatic glyceride biosynthesis in rats given CPIB did not show inhibition $(10,31)$, although more recent studies in humans have suggested that hepatic triglyceride secretion is lowered (11). Since the liver is the major postabsorptive site for serum triglyceride and lipoprotein formation, inhibition of these processes by pharmacological agents could contribute to reduced serum glyceride levels. Because of conflicting reports, these studies were initiated to determine the effects of CPIB on hepatic triglyceride formation measured in the intact animal and in liver homogenates.

The pathway of hepatic glycerolipid biosynthesis is shown in Fig. 6. Glycerol is removed from serum and converted to sn-glycerol-3-P by action of glycerokinase. sn-Glycerol-3-P also is derived from dihydroxyacetonephosphate. Diacylglycerophosphate is formed by sequential acylation of sn-glycerol-3-P (32) and the phosphate removed to form diglyceride. Esterification with long-chain acyl $\mathrm{CoA}$ derivatives yields triglyceride, or alternatively, reaction with cytidine diphosphate
(CDP) choline or CDP ethanolamine forms the corresponding phospholipids.

The rate of incorporation of glycerol $-{ }^{14} \mathrm{C}$ into glycerolipids was used to estimate the rate of glycerol conversion to glycerides in vivo. If significant changes in the specific activity of intermediates in this pathway do not occur, estimation of differences in hepatic triglyceride synthesis may be obtained by this technique. In control rats, the estimated rate of hepatic triglyceride formation was approximately $400 \mathrm{nmoles} / \mathrm{g}$ liver per $\mathrm{hr}$. This estimate is in close agreement with values obtained by different techniques in the rat and dog ( 31 , $33,34)$, although lower than values calculated in rats fed $10 \%$ glucose without chow (35) or starved (36). Since triglyceride released from the liver or hydrolyzed during the experimental period would not be included in the final calculation, the estimated rate of triglyceride formation must be considered a minimum approximation.

The studies in intact animals show that CPIB reduces the rate of incorporation of serum glycerol into hepatic and serum diglyceride and triglyceride. It is unlikely that this can be explained by a reduction in glycerol uptake by liver since the time course for serum glycerol $-{ }^{14} \mathrm{C}$ disappearance was identical in controls and rats given CPIB. In addition, hepatic glycerokinase activity was unaffected by CPIB administration. It is also unlikely that the variable increase in hepatic triglyceride content noted in some experiments, secondarily suppressed the rate of triglyceride formation in the liver. A rise in hepatic triglyceride content occurs 2-4 days after feeding diets high in fructose or glucose (37) and in choline deficiency (16), but both conditions are accompanied by increased rates of triglyceride formation as measured in vitro and in vivo (37).

The increase in hepatic triglyceride content, noted in some experiments, can not be explained by the reduction in hepatic triglyceride formation. The increase was prominent in rats fed diets high in glucose as noted previously (12). Under these latter conditions, an additional effect of CPIB on lipoprotein formation or release (12), hepatic triglyceride lipolysis, or the distribution of triglyceride between intracellular pools probably occurs. Present data is insufficient to choose between these various mechanisms. Possibly, the relatively high rate of triglyceride formation in rats fed high glucose diets containing CPIB (Fig. 2) permits an effect of CPIB on hepatic lipoprotein formation or release to be manifest.

In rats fed chow or high fat diets, hepatic triglyceride concentrations may fall $(5,29,30)$, remain constant $(10,27,28)$, or increase $(10,31)$. In the present studies, serum triglyceride levels fell uniformly in rats with either normal or raised hepatic triglyceride levels. Thus, variations in hepatic triglyceride concentration 
are not an essential component of the hypertriglyceridemic effect of CPIB. Further studies will be necessary to explain fully the cause and significance of hepatic triglyceride accumulation in some experiments.

The evidence reported here is not entirely comparable with a previous study of glyceride synthesis in rats fed CPIB for 14 days (10). Glyceride radioactivity was measured $4 \mathrm{hr}$ after glycerol ${ }^{14} \mathrm{C}$ administration in this latter experiment. At this time, virtually all serum nonlipid radioactivity is in glucose rather than glycerol, and hepatic lipid radioactivity has decreased from peak levels. Furthermore, isotope dilution effects were not excluded since no correction for the fall in serum glycerol or fatty acid concentration was made.

This previous study suggested that hepatic lipoprotein formation was reduced in rats given CPIB. Segal, Roheim, and Eder (12) also have reported a decrease in triglyceride release from the liver as soon as $12 \mathrm{hr}$ after ingesting CPIB in the rat. These observations could result from decreased glyceride and/or lipoprotein synthesis or impaired release of assembled lipoprotein from the liver. The present study suggests that reduced glyceride synthesis occurs at this early time period but does not exclude an additional effect of CPIB on lipoprotein metabolism.

The results of these experiments suggest an inhibition of hepatic glyceride and lecithin formation at a step between sn-glycerol-3-P and diglyceride in rats given CPIB. This possibility was explored further by studies in vitro. Addition of CPIB to rat liver homogenates caused a progressive fall in diglyceride and triglyceride formation. The concentration of CPIB which produced $20-35 \%$ inhibition approximates maximum serum concentrations. However, there is little information on hepatic levels of this agent or on intracellular compartmental distribution and no direct correlation of in vitro and in vivo concentrations is possible. It is of interest that many observations show that CPIB is bound by various proteins including albumin $(3,38)$.

The inhibition by CPIB in vitro was not related to reduction of long-chain acyl CoA formation or inhibition of phosphatidic acid phosphatase or diglyceride acylation (38). Moreover, the administration of CPIB to rats had no effect on the capacity for triglyceride formation from sn-glycerol-3-P in liver homogenates prepared from these animals. This observation suggests a possible direct inhibition by CPIB or a metabolite rather than an indirect effect on the concentration of enzymes in the pathway. Recent studies in this laboratory demonstrate that CPIB at concentrations of $0.1-$ $10.0 \mathrm{mM}$ inhibits sn-glycerol-3-P acyltransferase, the initial reaction in glycerolipid synthesis de novo (38). A $50 \%$ inhibition of this microsomal reaction occurs in the presence of $5.0 \mathrm{~mm}$ CPIB. Thus, both in vivo and in vitro studies are compatible with a direct inhibition of glyceride synthesis in the liver of rats given CPIB.

The present studies confirm previous observations of a fall in serum glycerol, which probably results from inhibition of lipolysis $(7,8)$. A similar decline in hepatic sn-glycerol-3-P has been reported and may be a consequence of the lower glycerol level or a result of changes in thyroid metabolism (14). Both of these latter changes may contribute to the sustained hypotriglyceridemic effect of CPIB by reduced hepatic triglyceride formation. However, the fall in serum triglyceride levels at $6 \mathrm{hr}$ coincided with a decline in estimated hepatic triglyceride formation in vivo before any of the other metabolic alterations occurred. This finding supports the hypothesis that the inhibition of hepatic glyceride synthesis is a major initial factor in the hypolipidemic effect of CPIB (1). However, other demonstrated effects of CPIB may contribute to or sustain the fall in serum triglyceride. These would include; inhibition of apolipoprotein synthesis either directly or as a consequence of decreased glyceride synthesis; impaired lipoprotein assembly or release; reduced adipose tissue lipolysis; inhibition of hepatic fatty acid synthesis; accelerated triglyceride removal from serum; altered thyroid hormone metabolism and reduction in adenyl cyclase activity (39). The relative importance of these additional mechanisms as well as other potential effects to the maintenance of hypotriglyceridemia has not yet been established.

It is of interest that CPIB failed to prevent the increase in glycerol incorporation into hepatic triglyceride produced by high carbohydrate diets (15), which agrees with results from studies in humans (40).

\section{ACKNOWLEDGMENTS}

This investigation was supported by U. S. Public Health Service Grants AM-09000 and ES-00129.

\section{REFERENCES}

1. Adams, L. L., W. W. Webb, and H. J. Fallon. 1970. Inhibition of hepatic triglyceride synthesis by clofibrate. Clin. Res. 18: 50. (Abstr.)

2. Oliver, M. F. 1962. Reduction of serum-lipid and uric acid levels by an orally active androsterone. Lancet. 1: 1321.

3. Thorpe, J. M., and W. S. Waring. 1962. Modification of metabolism and distribution of lipids by ethyl chlorophenoxyisobutyrate. Nature (London). 194: 948.

4. Avoy, D. R., A. Swyryd, and R. G. Gould. 1965. Effects of $\alpha$-p-chlorophenoxyisobutyrl ethyl ester (CPIB) with and without androsterone on cholesterol biosynthesis in rat liver. J. Lipid Res. 6: 369.

5. Azarnoff, D. L., D. R. Tucker, and G. A. Barr. 1965. Studies with ethyl chlorophenoxyisobutyrate (clofibrate). Metab. Clin. Exp. 14: 959. 
6. Nestel, P. J., and W. Austin. 1968. The effect of ethyl chlorophenoxyisobutyrate (CPIB) on the uptake of triglyceride fatty acids, activity of lipoprotein lipase and lipogenesis from glucose in fat tissue of rats. $J$. Atheroscler. Res. 8: 827.

7. Barrett, A. M. 1966. The effect of chlorophenoxyisobutyric acid on the release of free fatty acids from isolated adipose tissues, in vitro. Brit. J. Pharmacol. 26: 363.

8. Cenedella, R. J., J. J. Jarrell, and L. H. Saxe. 1968. Effects of ethyl-p-chlorophenoxyisobutyrate, clofibrate, on the plasma and red blood cell free fatty acids of the rat. J. Atheroscler. Res. 8: 903.

9. Duncan, C. H., M. M. Best, and A. Despopoulos. 1964. Inhibition of hepatic secretion of triglyceride by chlorophenoxyisobutyrate (CPIB).Circulation. 30: 7. (Abstr.)

10. Gould, R. G., E. A. Swryd, B. J. Coan, and D. R Avoy. 1966. Effects of chlorophenoxyisobutyrate (CPIB) on liver composition and triglyceride synthesis in rats. J. Atheroscler. Res. 6: 555.

11. Bierman, E. L., J. D. Brunzell, J. D. Bagdade, R. L. Lerner, W. R. Hazzard, and D. Porte. 1970. On the mechanism of action of Atromid-S on triglyceride transport in man. Trans. Ass. Amer. Physicians Philadelphia. 83: 211.

12. Segal, P., P. S. Roheim, and H. A. Eder. 1969. Mechanism of action of chlorophenoxyisobutyrate in hyperlipemic rats. Circulation. 40 (Suppl. III) : 182. (Abstr.)

13. Maragoudakis, M. E. 1969. Inhibition of hepatic acetyl coenzyme A carboxylase by hypolipidemic agents. $J$. Biol. Chem. 244: 5005

14. Westerfeld, W. W., D. A. Richert, and W. R. Ruegamer. 1968. The role of the thyroid hormone in the effect of p-chlorophenoxyisobutyrate in rats. Biochem. Pharmacol. 17: 1003 .

15. Fallon, H. J., and E. L. Kemp. 1968. Effects of diet on hepatic triglyceride synthesis. J. Clin. Invest. 47: 712.

16. Fallon, H. J., P. M. Gertman, and E. L. Kemp. 1969. The effects of ethanol ingestion and choline deficiency of hepatic lecithin biosynthesis in the rat. Biochim. Biophys. Acta. 187: 94.

17. Amenta, J. S. 1964. A rapid chemical method for quantification of lipids separated by thin-layer chromatography. J. Lipid Res. 5: 270.

18. Van Handel, E., and D. Zilversmit. 1957. Micromethod for direct determination of serum triglycerides. J. Lab. Clin. Med. 50: 152.

19. Laurell, S., and G. Tibbling. 1966. An enzymatic fluorometric micromethod for the determination of glycerol. Clin. Chim. Acta. 13: 317

20. Maruo, B., and A. A. Benson. 1959. Cyclic glycerophosphate formation from glycerophosphatides. J. Biol. Chem. 234: 254.

21. Robinson, J., and E. Z. Newsholme. 1969. Some properties of hepatic glycerol kinase and their relation to the control of glycerol utilization. Biochem. J. 112: 455.

22. Newsholme, E. A., J. Robinson, and K. Taylor. 1967. A radiochemical enzymatic activity assay for glycerol kinase and hexokinase. Biochim. Biophys. Acta. 132: 338.

23. Wittels, B., and R. Bressler. 1965. Lipid metabolism in the newborn heart. J. Clin. Invest. 44: 1639.
24. Young, D. L., and F. Lynen. 1969. Enzymatic regulation of 3-sn-phosphatidylcholine and triacylglycerol synthesis in states of altered lipid metabolism. J. Biol. Chem. 244: 377.

25. Hunninghake, D. B.. and D. L. Azarnoff. 1968. Clofibrate effect on catecholamine-induced metabolic changes in humans. Metab. Clin. Exp. 17: 588 .

26. Lowry, O. H., N. J. Rosebrough, A. L. Farr, and R. J. Randall. 1951. Protein measurement with the folin phenol-reagent. J. Biol. Chem. 193: 265.

27. Duncan, C. H., and M. M. Best. 1968. Influence of a terminal period of fasting on the serum and tissue lipid effects of ethyl chlorophenoxyisobutyrate (CPIB). Metab. Clin. Exp. 17: 681.

28. Best, M. M., and C. H. Duncan. 1964. Hypolipemia and hepatomegaly from ethyl chlorophenoxyisobutyrate (CPIB) in the rat. J. Lab. Clin. Med. 64: 634.

29. Kokatnur, M. G., and G. T. Malcom. 1970. Lipid lowering influence of ethyl-p-chlorophenoxyisobutyrate in liver of rats fed high fat diets. Metab. Clin. Exp. 19: 120.

30. Hoak, J. C., W. E. Conner, M. L. Armstrong, and E. D. Warner. 1968. Effect of clofibrate on serum and hepatic lipids in nephrotic rats. Lab. Invest. 19: 370.

31. Gould, R. G., E. A. Swyryd, D. Avoy, and B. Coan. 1967. The effects of $\alpha$-p-chlorophenoxyisobutyrate on the synthesis and release into plasma of lipoproteins in rats. Progr. Biochem. Pharmacol. 2: 345.

32. Lamb, R. G., and H. J. Fallon. 1970. The formation of monoacylglycerophosphate from sn-glycerol-3-phosphate by a rat liver particulate preparation. J. Biol. Chem. 245: 3075 .

33. Heimberg, M., A. Dunkerley, and T. O. Brown. 1966. Hepatic lipid metabolism in experimental diabetes. I. Release and uptake of triglycerides by perfused livers from normal and alloxan-diabetic rats. Biochim. Biophys. Acta. 125: 252.

34. Gross, R. C., E. H. Eigenbrodt, and J. W. Farquhar 1967. Endogenous triglyceride turnover in liver and plasma of the dog. J. Lipid Res. 8: 114.

35. Baker, N., and M. E. Schotz. 1964. Use of multicompartmental modes to measure rates of triglyceride metabolism in rats. J. Lipid Res. 5: 188.

36. Baker, N., and M. C. Schotz. 1967. Quantitative aspects of free fatty acid metabolism in the fasted rat J. Lipid Res. 8: 646.

37. Fallon, H. J., and M. B. Waddell. 1971. Increased hepatic triglyceride synthesis and hypertriglyceridemia in rats fed diets high in glucose or fructose. Clin. Res. 19: 81. (Abstr.)

38. Lamb, R. G., and H. J. Fallon. 1971. Inhibition of monoacylglycerophosphate synthesis by chlorophenoxyisobutyrate and beta benzalbutyrate. Fed. Proc. Fed. Amer. Soc. Exp. Biol. 30: 275. (Abstr.)

39. Greene, H. L., R. H. Herman, and D. Zakim. 1970. The effect of clofibrate on rat tissue adenyl cyclase. Proc. Soc. Exp. Biol. Med. 134: 1035.

40. Zakim, D., and R. H. Herman. 1969. The effect of clofibrate on the serum triglyceride concentration in normal males fed high-sucrose diets. J. Atheroscler. Res. 10: 91 